\title{
ERRATUM
}

\section{Drug-inducible and simultaneous regulation of endogenous genes by single-chain nuclear receptor-based zinc-finger transcription factor gene switches}

L Magnenat, LJ Schwimmer and CF Barbas III

Gene Therapy (2008) 15, 1246; doi:10.1038/gt.2008.136

Correction to: Gene Therapy (2008) 15, 1223-1232; doi:10.1038/gt.2008.96

Following the advanced online publication of this article, the authors noticed that one of the concentrations was printed incorrectly in the legend of Figure 3. The correct concentration used for the treatment with 4-hydroxytamoxifen (4-OHT) is $(100 \mathrm{nM})$.

The publisher apologizes for this error. 